\title{
DEMOCRACIA E BENS NATURAIS NA BOLÍVIA DO VIVIR BIEN: UMA CRÍTICA A PARTIR DA COLONIALIDADE E DA DEPENDÊNCIA
}

\author{
DEMOCRACY AND NATURAL GOODS IN BOLIVIA OF VIVIR BIEN: A \\ CRITICAL FROM COLONIALITY AND DEPENDENCE
}

\author{
Bernardo Xavier dos Santos Santiago* \\ Enzo Bello**
}

\begin{abstract}
Resumo: O presente artigo objetiva pensar criticamente como se dá a relação entre democracia e bens naturais na Bolívia a partir das categorias colonialidade e dependência. A hipótese de base da pesquisa é que a democracia avança no país na medida em que novos e tradicionais sujeitos políticos emergentes resistem a processos de expropriação e mercantilização da natureza, afirmando modos de vida em harmonia com a Madre Tierra e produzindo novos paradigmas de relações e interações entre seres humanos e meio ambiente. Assim, busca-se situar os impasses gerados a partir da renovação do extrativismo como paradigma de desenvolvimento econômico para a efetivação dos dispositivos de democracia da carta do Novo Constitucionalismo, conformando um campo aberto de disputa dos sentidos do Vivir Bien. Adota-se a metodologia da pesquisa interdisciplinar com orientação epistemológica na Teoria Crítica através da conjunção dos marcos teórico-metodológicos do materialismo histórico e dialético, e do pensamento descolonial. Adotam-se, ainda, os raciocínios indutivo e dedutivo, numa abordagem jurídico-sociológica, pelos modos de pesquisa qualitativa, o que envolve as técnicas de pesquisas de revisão bibliográfica e análise documental.
\end{abstract}

Palavras-chave:Bolivia; Bens naturais; Democracia; Colonialidade; Dependência;

Abstract: Thispaperaims to thinkcritically, from the categories "coloniality" and "dependence",abouthowtherelationshipbetweendemocracy and natural goodsworksin Bolivia. The basic research hypothesis is that democracy goes ahead in that country according to the new and traditional emergent political subjects resistance to processes of disposession and merchandizing/commodification of nature, affirming ways of life in harmony with the Madre Tierra and producing new paradigms of relationships and interactions between human beings and environment. Thus, this study seeks to place the deadlocks created from the renewal of extractivism as a paradigm of economic development. And to the effectiveness of democratic dispositions on one of the main texts of the so called New Constitutionalism, generating an opened field of meanings dispute of the Vivir Bien. It is adopted the interdisciplinary

\footnotetext{
* Mestrando no Programa de Pós-Graduação em Direito Constitucional da Universidade Federal Fluminense (UFF) e bolsista CAPES. E-mail: bernardoo.xavier@gmail.com

** Pós-Doutor em Direito pela Universidade do Vale do Rio dos Sinos (UNISINOS). Doutor em Direito pela Universidade do Estado do Rio de Janeiro (UERJ). Professor Adjunto III da Faculdade de Direito e do Programa de Pós-Graduação em Direito Constitucional da Universidade Federal Fluminense (UFF). Coordenador do Núcleo de Estudos e Projetos Habitacionais e Urbanos (NEPHU) - UFF. Editor-chefe da Revista Culturas Jurídicas (www.culturasjuridicas.uff.br). Professor do Programa de Pós-graduação em Direito da Universidade Estácio de Sá (UNESA). Consultor da Coordenação de Aperfeiçoamento de Pessoal em Nível Superior (CAPES). E-mail: enzobello@gmail.com
} 
methodology of research, with epistemological reference in the Critical Theory, through a link between the theoretical and methodological guidelines of the historical and dialectic materialism, and the decolonial thought. It is used, already, inductive and deductive reasoning, in a sociological and legal approach, through the tools of qualitative research, which involve two techniques of research: bibliographical review and documentary analysis.

Keywords: Bolivia; Natural Goods; Democracy; Coloniality; Dependence;

\section{INTRODUÇÃO}

Este trabalho parte da noção do pensamento descolonial de que a Modernidade, através da colonialidade, produz um padrão de poder etno e eurocentrado, criando diferenças raciais para promover a expansão do capitalismo através da exploração do trabalho de populações subalternizadas e da apropriação dos bens naturais dos territórios da periferia mundial (QUIJANO, 2000). Nesse sentido, o processo histórico latino-americano, em especial o boliviano, desponta como um retrato do modo colonial de acumulação pelo extrativismo operado a partir de estruturas multifacetárias da colonialidade.

Os modos de produção capitalista e colonial se organizam com base na mercantilização expansiva dos bens comuns, de tal forma que qualquer abordagem do tema democracia na América Latina, mais especificamente na Bolívia, deve necessariamente passar pelas questões ambientais. Esta que, conforme aponta o autor ecossocialista James O’Connor(O'CONNOR, 1998), é a segunda contradição do capitalismo , a que resulta da exploração predatória do meio ambiente ${ }^{1}$. Sustentamos aqui que não há de existir democracia se não houver titularidade, apropriação, uso e controle popular das riquezas naturais. $\mathrm{O}$ objetivo do trabalho é, pois, situar criticamente as relações entre meio ambiente e democracia na Bolívia, no contexto recente do seu constitucionalismo pluricultural.

As estruturas coloniais no Sul Global, em seu recorte na América Latina, condicionam há séculos seu papel de produtora e exportadora de matérias primas na divisão internacional do trabalho, resultando daí processos amplos de exploração da mão de obra barata, mas também de degradação ambiental. Na Bolívia, a recente manifestação do Poder Constituinte emergiu de conflitos socioambientais, mais propriamente da organização de bloco popular que se opõe às políticas de neoliberais de privatização dos recursos naturais, que aprofundam o modo colonial de desenvolvimento pelo extrativismo.

A hipótese de base da pesquisa aqui apresentada é de que a Pachamamaestá no centro da participação popular no país em virtude dos modos de vida e das cosmovisões dos povos originários. A democracia boliviana avança na medida em que novos e tradicionais R. Fac. Dir. UFG, v. 41, n.1, p. 103-121, jan. / jun. 2017 
sujeitos políticos emergentes resistem a processos de expropriação e mercantilização da natureza, afirmando modos de vida ancestrais em harmonia com a Madre Tierra e produzindo novos paradigmas de relações e interações entre os seres humanos e o meio ambiente. $\mathrm{Na}$ primeira parte do artigo, os conflitos socioambientais aparecem no centro dos dois grandes ciclos de manifestações na Bolívia deste século, que ainda que se realizem em conjunturas políticas e normativas distintas, e têm em comum as atividades extrativistas.

$\mathrm{Na}$ segunda parte são apresentados os institutos normativos de participação popular e proteção ambiental previstos na Nova Constituição Política do Estado Plurinacional de Bolívia (NCPE), organizados a partir do Vivir Bien ${ }^{2}$ e da Plurinacionalidade, compreendendo, entretanto, as limitações do constitucionalismo e do sistema jurídico para a produção e efetivação de direitos.

$\mathrm{Na}$ terceira etapa, situa-se o atual debate sobre o extrativismo no país, principal impasse da consolidação normativa, disputando os sentidos aberto e abstrato do Vivir Bien. A transposição de um conceito cultural e ancestral para a institucionalidade, ou seja, a sua passagem do local para o macro revela uma série de desafios e contradições para as práticas e discursos socioambientais, que são modelados a partir da sua aplicação nos campos jurídico e econômico.

Adota-se a metodologia da pesquisa interdisciplinar com orientação epistemológica na Teoria Crítica, através da conjunção dos marcos teórico-metodológicos do materialismo histórico e dialético, e do pensamento descolonial ${ }^{3}$. Adotam-se, ainda, os raciocínios indutivo e dedutivo, numa abordagem jurídico-sociológica pelos modos de pesquisa qualitativa, o que envolve as técnicas de pesquisas de revisão bibliográfica e análise documental.

2 OS BENS NATURAis NO CENTRO dA PARTICIPAÇÃO POPULAR NA BOLÍVIA

É possível identificar na Bolívia do século XXI dois grandes ciclos de manifestações populares relacionadas a conflitos socioambientais, mais propriamente aos impactos sociais e ambientais produzidos pelas atividades extrativistas, cujo marco divisor é o governo do presidente Evo Morales e do Movimiento al Socialismo (MAS). O tema dos recursos naturais tem estado presente nas demandas dos movimentos indígenas nos países andinos nos últimos anos, quando estes percebem sua identidade étnica como povos em um 
determinado território, assim como sua posição de classe, aprofundando e ampliando sua percepção de luta política (ALBÓ, 2009).

Um primeiro ciclo entre 2000 e 2005 é marcado pela contestação ao modelo de Estado colonial e às políticas neoliberais, tendo seu ápice na Guerra da Água e na Guerra do Gás, e um segundo já sobre a vigência da Nova Constituição Política do Estado Plurinacional de Bolívia, que tem nas Marchas Indigenas en Defensa del TIPNIS seu maior expoente.

Conhecido como Ciclo Rebelde(CABEZAS, 2007), o período se inicia com a Guerra da Água, ocorrida em abril de 2000 em Cochabamba contra a Lei 2029 de Água Potável e Esgoto, que privatizava a gestão da água em favor da empresa transnacional Bechtel. O objetivo do governo do então presidente Hugo Banzer (1997-2001) era privatizar também os sistemas de irrigação, que eram administrados pelas comunidades rurais conforme seus usos e costumes (GUIMARÃES, 2014, p. 173).

Já que o abastecimento de água cobria também uma parte da área urbana, os comitês urbanos de abastecimento de água, a Federação de Trabalhadores Fabris de Cochabamba, grupos profissionais, ambientalistas e cocaleros e ayllus da zona andina se uniram na Coordenadoria de Defesa da Água e da Vida, conjugando interesses comuns de diversos setores, urbanos e rurais, em torno da questão (GUIMARÃES, 2014, p. 174). As jornadas de protesto e mobilização culminaram na rescisão do contrato de concessão dos serviços de água, representando um triunfo social que contribuiu pare gerar um estado de disponibilidade coletiva, questionando a legitimidade das políticas neoliberais no país (GUIMARÃES, 2014, p. 175).

A vitória na Guerra da Água foi o elemento chave para desencadear outros protestos de contestação à presença dos investimentos neoliberais e do capital transnacional na região. Os conflitos relacionados ao questionamento e à critica ao modelo racista e excludente de Estado e sociedade se acirraram, fazendo com que as comunidades camponesas-indígenas incorporassem em suas demandas as propostas e demandas relacionadas à igualdade racial, ao autogoverno, às novas formas de gestão política indígena e à incorporação de culturas na esfera da legitimidade (GUIMARÃES, 2014, p. 176).

Posteriormente, em 2003, após diversas mobilizações populares cada vez mais intensificadas, a Guerra do Gás se iniciou como uma culminação dos protestos realizados no mesmo ano (GUIMARÃES, 2014, p. 179) a partir de sujeitos sociais coletivos já mobilizados, em especial as comunidades indígenas. Diante da disposição do governo boliviano de manter 
uma política que prezasse pelas privatizações e exportações dos recursos naturais, o então presidente Gonzalo Sanches de Lozada determinou a venda do gás natural boliviano aos Estados Unidos através dos portos chilenos. Em contraposição, as comunidades indígenas e camponesas se mobilizaram através do bloqueio de estradas e a paralisação geral em El Alto, reivindicando a nacionalização do gás, a saída do presidente, a revogação do decreto de hidrocarbonetos (Decreto 27.209/03) e a não repressão aos grupos sociais mobilizados(LEONEL JÚNIOR, 2015, p. 67-68).

Como resultado, apesar da retaliação por parte do governo e de diversas mortes em conflitos armados, a Agenda de Outubro foi elaborada, corroborando com a construção de uma pauta de reivindicações dos movimentos sociais articulados com a nacionalização dos recursos naturais e, na sequência, a própria realização de uma Assembleia Constituinte (LEONEL JÚNIOR, 2015, p. 68). Em razão das forças de mobilização popular, Sanchez de Lozada renunciouà presidência, que passou a ser ocupada por Carlos Mesa. Este, por sua vez, iniciou reformas políticas para garantir a anistia dos sujeitos políticos ligados aos movimentos sociais e participantes das mobilizações de 2003, incluindo o líder cocalero Evo Morales (LEONEL JÚNIOR, 2015, p. 68).

Em 2005, diante da instabilidade política e da recusa do então presidente de aprovar a nacionalização dos hidrocarbonetos, as mobilizações são retomadas. O interessante é que boa parte dos sujeitos que se organizaram nessas lutas, desde o ano 2000, vivem em forma comunitária, o que foi fundamental para garantirem a autonomia e a manutenção das mobilizações por longos períodos(LEONEL JÚNIOR, 2015, p. 68).

$\mathrm{Na}$ Bolívia, a ideologia indianista pôde se expandir durante as reformas neoliberais da economia, a partir do fortalecimento de laços comunitários, sendo capaz de oferecer explicações ao drama coletivo com a "articulação política das experiências cotidianas de exclusão social, discriminação étnica e memória social comunitária de campesinos índiosdeixados à suasorte por um Estado empresário" (GARCIA LINERA, 2008, p. 388 $)^{4}$. O indianismo politiza elementos até então utilizados pela "Modernidade" para bloquear e legitimar a restrição dos mecanismos de inclusão e de mobilidade social, como a cultura, o idioma, a história e a cor da pele, transformando-os em instrumentos desgastantes da ideologia neoliberal e componentes de uma "ideologia comunitarista de emancipação". Paralelamente, este indianismo "tornará coesa umaforça de massamobilizável, insurreicional, e eleitoral, logrando politizar o campo político discursivo e consolidando-se comoumaideologia comprojeção estatal" (GARCIA LINERA, 2008, p. 389) ${ }^{5}$. 
Com a intensificação dos protestos, Mesa renunciou e se afastou da presidência em junho de 2005, tendo o presidente da Corte Suprema de Justiça assumido o cargo até a realização de novas eleições. No mesmo ano, Evo Morales foi eleito, fechando o ciclo de protestos iniciado em 2000. O que se pode depreender do ciclo de protestos iniciado com a Guerra da Água é, essencialmente, o questionamento da legitimidade do Estado e a interação violenta na relação deste com os setores mobilizados, conforme sustenta Alice Guimarães (GUIMARÃES, 2014, p.182).

Era marcante o quanto o Estado tentava definir os moldes das relações entre os grupos étnicos e as relações deles com a natureza, a partir do paradigma de democracia liberal e de cidadania pautada em instituições republicanas, incompatíveis com os símbolos de poder indígena e do sistema territorial além do Estado, o que demandou a construção de novas noções de cidadania, Estado, território e poder. Como resultado desse novo ambiente interativo, o Estado foi perdendo sua legitimidade e, por conseguinte, sua capacidade de imposição da autoridade constitucional e de controle da ordem interna (GUIMARÃES, 2014, p. 182).

Deve ser destacado que o que torna possível a ascensão de um bloco histórico constituinte é o Pacto de Unidade ${ }^{6}$ formado por movimentos camponeses indígenas, que se tornaram a principal base de sustenção de Evo Morales. Este Pacto de Unidade foi rompido durante o segundo ciclo de grandes manifestações, objeto deste tópico, quase 10 anos após sua consolidação. A tensão territorial no Território Indígena y Parque Nacional Isiboro-Secure (TIPNIS ${ }^{7}$ ) coloca em xeque as políticas de participação popular e desenvolvimento do governo, promovendo rupturas na sua base de apoio.

A política de desenvolvimento do atual governo prevê a construção de uma estrada que atravessa o TIPNIS, integrando-o ao sistema de vias que interliga as principais cidades da Bolívia e ao "Eixo Andino" da Iniciativa de Integração da Infraestrutura Sulamericana (IIRSA) que, por sua vez, se conecta com o Eixo Interoceânico Central e o Eixo Perú-Brasil-Bolívia ${ }^{8}$. A construção da estrada é casada com a concessão de lotes de petróleo que abarcam a região do TIPNIS, para exploração e exportação pela Petroandina e pela Petrobrás. A proposta de carretera contaria ${ }^{9}$ com financiamento do BNDES, a ser construída pela empreiteira brasileira OAS (PAZ, 2012).

O projeto de construção da estrada deflagrou um grande conflito com as comunidades indígenas que habitam o TIPNIS, sendo a sua maior expressão a VIII Gran Marcha Indígena en Defensa del TIPNIS, los territorios, la dignidad, la vida y los derechos 
de los pueblos indígenas, de agosto à outubro de 2011, que reuniu cerca de quinhentos mil manifestantes na sua chegada à La Paz e logrou a aprovação, na Asembleia Nacional, da Leyn ${ }^{\circ} 180$, que declara intangível o território, assegurando legalmente a não construção da estrada. Uma nova marcha, desta vez pró-empreendimento, foi mobilizada por produtores cocaleros revertendo os efeitos da intangibilidade, com a aprovação da Ley $\mathrm{n}^{\mathbf{0}} 222$, que preveria uma consulta prévia - posterior, no caso concreto. ${ }^{10}$

O conflito segue pendente, tornando-se um grande expoente das fraturas das políticas de desenvolvimento dos governos da região diante da sua inserção periférica no capitalismo global, mas também como expressão da vitalidade dos movimentos de resistência. As disputas nos territórios ganham especial relevo diante da corrida capitalista pelo controle e exploração dos bens naturais, que, por sua vez, na Bolívia, seguem como depositários de valores não econômicos ${ }^{11}$.

\section{O VIVIR BIEN E OS DIREITOS DA MADRE TIERRA: ASPECTOS} NORMATIVOS

Os movimentos indígenas e campesinos passam a ter reconhecidas normativamente na NCPE uma série de direitos e políticas organizadas em torno do Vivir Bien e da Plurinacionalidade. Políticas que preveem a ampliação institucional dos mecanismos de participação popular e consultas prévias, autonomias e autogoverno de povos originários, que se chocam, em alguns momentos, com a previsão constitucional do controle estatal das atividades de extração, produção e beneficiamento de recursos naturais. Em ambiguidade, o fato de articularem densidade democrática e direitos da Natureza, a partir da inclusão modos de vida e cosmovisões originárias, e seu uso estratégico pelo Estado.

Devem ser destacados, entretanto, os riscos da análise dos instrumentos normativos de participação popular e proteção ambiental a partir das limitações do constitucionalismo sob dois prismas: i) o "fetichismo constitucional", a ilusão da realização plena da cidadania quando confi(n)ada ao Direito e à Constituição(BELLO, 2010); ii) o novo constitucionalismo na Bolívia continua sendo constitucionalismo, logo, um fenômeno originado na Modernidade europeia e transplantado para a América Latina, hoje e outrora, através de uma dinâmica de colonialidade do poder e do saber (QUIJANO, 2000). Ou seja, por mais que se inove e modifique em matéria de Constituição, a concretização desta com o 
resgate das tradições ancestrais e com as vislumbradas transformações sociais estará sempre condicionada pelas condições materiais de poder(BELLO, 2015).

A Constituição boliviana de 2009 prevê a democracia comunitária e possibilita a eleição, designação ou nomeação de parlamentares indígenas, representantes e autoridades dos territórios autônomos por meio de procedimentos próprios das nações e povos indígenas originários e campesinos (art. 11). É garantida a livre determinação das nações e povos originários, que consiste no direito à autonomia, ao autogoverno, ao reconhecimento da cultura e das instituições e da consolidação dos territórios (art. 2). Prevê que os territórios indígenas autônomos são instancias subnacionales de governo, nas quais se aplicam a justiça indígena e usos e costumes para a seleção dos governantes (art. 289 e 296). Medidas administrativas ou legislativas que afetarem os povos indígenas ou a exploração de recursos naturais não renováveis em seus territórios obrigatoriamente serão precedidas por consulta (art. 30).

O Estado incorpora e promove como seus princípiosético-morais princípios indígenas como: o ama qhilla, ama llulla, ama suwa (não seja flojo, não seja mentiroso, não seja ladrão), o suma qamaña (o bem viver), o ñandereko (vida harmoniosa), o teko kavi (vida boa), o ivi maraei (terra sem males) e o qhapaj ñan (caminho ou vida nobre) (art. 8.1). Estabelece como função essencial do Estado constituir uma sociedade justa e harmoniosa, pavimentada na descolonização, sem discriminação nem exploração, para consolidar as identidades plurinacionais (art. 9.1). Reconhece a justiça indígena, em igual hierarquia com a justiça ordinária (art. 179.2). O art. 33 da Constituição boliviana acolhe o direito de outros seres: "As pessoas têm direito a um meio ambiente saudável, protegido e equilibrado. $O$ exercício deste direito deve permitir aos indivíduos e coletividades das presentes e futuras gerações, além de outros seres vivos, desenvolvendo-se de maneira normal e permanente" ${ }^{\prime 2}$.

A população tem direito à participação na gestão ambiental e à consulta prévia e informada sobre decisões que possam afetar a qualidade do meio ambiente (art. 341) e sobre decisões que dizem respeito à exploração de recursos naturais em um determinado território (art. 350). Em áreas protegidas sobrepostas a territórios indígenas e campesinos, a gestão será realizada em sujeição aos usos e costumes, desde que respeitados os objetivos de criar essas áreas (art. 386).

Prevê a exclusividade do Estado na utilização do patrimônio natural (art. 344); declara que os recursos naturais são estratégicos e de interesse nacional (art. 346), sendo de competência administrativa do Estado, que deve ter controle e gestão na exploração, 
industrialização, comercialização e transporte dos recursos naturais (art. 349); também detém a propriedade dos Hidrocarbonetos (art. 357), das riquezas mineralógicas (art. 367); Os recursos hídricos não serão objeto de apropriação privada e seus serviços não serão sequer concedidos (art. 371), promovendo participação social na sua gestão, e respeito aos usos e costumes das autoridades locais, comunidades, agricultores e organizações indígenas (art. 372).

Para as eleições ao Legislativo, o texto constitucional define a participação paritária de homens e mulheres e garante a participação proporcional das nações e povos indígenas (art. 146 e 147).

Cria o Tribunal Agroambiental como órgão especial competente para julgar demandas sobre atos que atentem contra a fauna, a flora, a água e o meio ambiente, além de práticas que põem em perigo o sistema ecológico e a conservação de espécies ou animais (art. 198), que elege seus membros mediante sufrágio universal para mandatos de seis anos, sem direito a reeleição. Os mesmos procedimentos se aplicam ao Consejo de la Magistratura, ao Tribunal Supremo de Justicia e ao Tribunal Constitucional (art. 182, 183, 188, 194 e 197).

A Constituição da Bolívia regulamenta a revogação de todos os cargos eletivos, com exceção dos membros do Poder Judiciário, imunes a tal mecanismo. A solicitação da revogação do mandato poderá ser feita após transcorrida a metade do período e antes do último ano do mandato. E, assim como nos outros países, só uma vez por mandato. Para que se inicie, o processo deve contar com o apoio de ao menos $15 \%$ dos cidadãos da circunscrição do representante questionado (art. 240). A Constituição boliviana somente prevê a necessidade de referendo para qualquer reforma constitucional, desde que não afete suas bases fundamentais, direitos e garantias. Nesse caso, as alterações serão feitas mediante Assembleia Constituinte Plenipotenciária, ativada mediante referendo (art. 411).

$\mathrm{Na}$ Bolívia, os tratados internacionais deverão ser submetidos a referendo vinculante e prévio quando versarem sobre questões limítrofes, integração monetária, integração econômica estrutural e cessão de competências institucionais a organismos internacionais ou supranacionais (art. 257). Também outros tipos de tratados podem ser submetidos a referendo, desde que o pedido conte com o apoio de não menos que $5 \%$ dos cidadãos inscritos na lista de eleitores (art. 259).

O controle social é exercido por meio da Función de Control, Defensa de la Sociedad y del Estado (Ministerio Publico, Defensoria del Pueblo e Contraloría General de la República) (art. 213 a 231). A sociedade civil organizada tem direito a fiscalizar e 
denunciar possíveis casos de revogação, e a controlar a gestão pública, em todos os níveis estatais, e qualquer empresa que use recursos públicos (art. 241, 242).

Os cidadãos também podem propor leis, emendas constitucionais (o quórum neste caso é de $20 \%$ do eleitorado) e convocar uma Assembleia Constituinte (art. 162, 411), além de estabelecer a participação da sociedade civil organizada no desenho das políticas públicas e da gestão estatal, criando a figura da participación y control social (art. 241, 242).

4 A DISPUTA DO SENTIDO DO VIVIR BIEN NA ECONOMIA EXTRATIVISTA E DEPENDENTE

Como afirmado, a construção de um Novo Estado, a proteção ambiental e a participação popular positivadas na nova carta magna boliviana estão sujeitas à concretude da vida social e às relações de poder. A Bolívia, assim como os demais países da América Latina, reproduz um padrão de economia primarizada, centrada na exploração dos bens naturais para exportação, ampliando a degradação ambiental. Eduardo Gudynas inscreve a Bolívia no que seria o "neo-extrativismo progressista".

\footnotetext{
Neste caso se repete a apropriaçãomaciça de recursos naturais para exportação, por meio de enclaves produtivos, e se repetem os impactos sociais e ambientais. Mas o protagonismo estatal é maior, e emalguns casos aparece sob a forma de controles mais rigorosos, maioresníveis de tributação ou regalias, ou pelo regresso de empresas estataisassumindo o controle de distintos projetos (GUDYNAS, 2011, p. 387) ${ }^{13}$.
}

A matriz colonial de desenvolvimento extrativista remete à formação do capitalismo internacional, na qual as atividades mineradoras na América Latina garantem inicialmente a expansão dos meios de pagamento e do fluxo de mercadorias, possibilitando o desenvolvimento do capitalismo nos países de capitalismo central. Esta dinâmica inaugura a divisão internacional do trabalho e, com ela, as relações de dependência dos países periféricos, pelas quais as relações de produção são organizadas e reorganizadas de forma a assegurar a reprodução ampliada da dependencia(MARINI, 2000).

O processo de pilhagem de recursos naturais na Bolívia é amplamente descrito na célebre obra "Veias abertas da América Latina", na qual Eduardo Galeano discorre sobre a exploração da prata em Potosí. A formação do capitalismo industrial na Inglaterra do século XVIII só foi possível em virtude dos minerais apropriados do território boliviano. Existe 
alternativa libertadora e efetivação de direitos ambientais nas relações postas pelas relações econômicas dependentes?

O aprofundamento das políticas de extrativismo no novo períodohistórico pós eleição do Evo Morales, já sob os marcos principiológicos do Vivir Bien, passa a opor dois blocos, naquele que parece ser o principal impasse dos governos progressistas da região(BORÓN, 2014): i) os "pachamamicos", que questionam a natureza da atividades extrativistas e, portanto, o modo de o ser humano e o Estado se relacionarem com a natureza e os impactos sociais e ambientais inerentes à sua manutenção; ii) os "extrativistas", que defendem a atividade quando realizada sobre outro marco organizacional, como fortalecimento do papel do Estado na economia e indutora do financiamento de políticas públicas redistributivas ${ }^{14}$.

Eduardo Gudynas elabora uma série de teses críticas ao neoextrativismo dos governos progressistas da região, dentre os quais desponta o governo Evo Morales. O autor destaca que se desenvolve um extrativismo de novo tipo, diferente do praticado por governos conservadores, mas que segue promovendo impactos sociais e ambientais, impulsionando as mais diversas reações e oposições sociais:

(...) a chegadaaogoverno de Evo Morales e do MAS na Bolívia, rapidamentedesembocouemumamudança substancial na imposiçãotributária e regalias das empresas, renegociação dos contratos, e um Estado que deixa de ser um mero espectador e passa a se constituir emumator chave para essessetores (GUDYNAS, 2009, p. 193) ${ }^{15}$.

No mesmo sentido, aludindo ao já apresentado conflito em torno do TIPNIS, Raul Prada Alcoreza aponta:

(...) Os dois projetos não podem coexistir no processo, são opostos; um se coloca na continuidade da mesma civilização moderna, capitalista, desenvolvimentista e extrativista, o outro aponta para abolir esta civilização, abrindo a possibilidade civilizatória alternativa fazendo emergir configurações culturais inibidas pelos colonialismos e o capitalismo, atualizando-os e combinando-os com formas autogestionárias e solidárias contemporâneas. Este projeto se opõe abertamente ao desenvolvimentismo e ao extrativismo, se encaminha para restaurar as complementariedades dinâmicas com os ecosistemas, seres, ciclos vitais interrelacionados e integrados nas formas complexas de reprodução da vida. Não deve nos surpreender, então, os conflitos que se dão entre o governo e as nações e povos indígenas originários, pois o governo se converteu na expressão política e institucional do projeto de continuidade capitalista, desenvolvimentista, extrativista e de monoculturas. ¿Por que Isso aconteceu? A contradição era latente, mas não teve as condições de possibilidade para mostrar-se; uma coisa era lutar contra os governos neoliberais e o projeto 
neoliberal em curso e outra coisa é abolir o Estado-nação, construir o Estado plurinacional comunitário e autônomo, na perspectiva do modelo civilizatório do Vivir Bien, que se baseia no respeito dos direitos dos seres, componentes e ciclos vitais da Madre Tierra (PRADA, 2011, p. 5) ${ }^{16}$.

Por outro lado, Atílio Borón afirma que as cosmologias "pachamamicas" não podem ser analisadas de forma apartada da geopolítica internacional. Segundo o autor, os países da América Latina e Caribe passam por um período de desindustrialização e reprimarização da economia em virtude da recente crise geral do capitalismo, mas também pela inflexão do neoliberalismo e das condicionantes impostas pelo Banco Mundial e pelo Fundo Monetário Internacional. Isto acentuou a dependência de saldos oriundos da exportação de matérias primas para equilibrar o saldo comercial.

Em algumas versões, este pachamamismo chegou tãolonge como para exigir aos governos dos países de esquerda o abandono de qualquer pretensão de explorar recursos naturais, colocando aqueles diante de um cruel e difícil dilema: como conciliar a necessidade de responder às renovadas demandas de justiça distributiva - elevadas pela população que sofreu séculos de opressão e miséria - com a intangibilidade da natureza? (BORÓN, 2014, p. $138)^{17}$.

Sustenta o autor, apesar de suas preocupações ecológicas, que qualquer análise não deve descartar o fato de que os ingressos advindos das exportações extrativistas têm servido para financiar amplos programas de políticas sociais, ponto mais que necessário em momentos como os atuais. Destaca, ademais, que na Bolívia aproximadamente um terço da população recebe algum tipo de transferência de renda pelo governo nacional, através de programas como o Juancito Pinto, Juana Azurduy e o Renta Dignidad(BORÓN, 2014, p. 141).

Em linha semelhante, o sociólogo e atual vice-presidente Alvaro Garcia Linera sustenta a exploração dos recursos naturais como etapa:

O extrativismo não é um destino; pode ser um ponto de partida para sua superação. Certamente no extrativismo se condensa toda uma distribuição territorial da divisão do trabalho mundial, distribuição colonial. Mas para romper essa subordinação colonial não é suficiente encher a boca de injúrias contra o extrativismo, deixar de produzir e afundar em maior miséria o povo, para que logo regresse à direita e mediante o extrativismo satisfaça parcialmente as necessidades básicas da população. Esta é precisamente a armadilha conservadora dos críticos do extrativismo. Em sua liturgia conservacionista, mutilam as forças revolucionárias e os governos revolucionários dos meios materiais para satisfazer as necessidades da população, para gerar riqueza e distribuí-la com justiça, e criar sobre ele uma 
nova base material não extrativista que preserve e amplie os benefícios da população trabalhadora (GARCIA LINERA, 2012, p. 6) ${ }^{18}$.

Esta disputa é o pano fundo de discussões acerca dos sentidos possíveis do conceito Vivir Bien, enquanto alternativa de desenvolvimento ou alternativa ao desenvolvimento (ACOSTA, 2016). O Vivir Bien, categoria relacionada a elementos da cosmovisão de povos originários, principalmente Suma Qamaña (Aymara) e Sumak Kawsay (Quichua) - mas que também encontra correlação com o Ñendereko e Teko kavi (Guaranî) propõe o reconhecimento de formas coletivas, em todas as suas dimensões, de produção harmoniosa da vida.

A transposição de um conceito cultural e ancestral para a institucionalidade, ou seja, a sua passagem do local para o macro revela uma série de desafios e contradições para as práticas e discursos socioambientais que se modelam diante da aplicação nos campos jurídico e econômico de um principio constitucional que se torna abstrato. $\mathrm{O}$ risco de sua fetichização é permanente, tal como ocorre com o direito fundamental à dignidade da pessoa humana no ordenamento brasileiro, isto é, a ilusão na sua plena satisfação quando confi(n)ado ao Estado e ao constitucionalismo.

O impasse que se coloca entre os sujeitos em conflito - ambos reivindicando a natureza emancipatória e descolonizadora de seus atos - é de ordem principiológica, mas também uma questão de tática política. Isso diante de um contexto de integração regional a partir dos governos progressistas da América Latina, mas também de reorganização do capitalismo mundial a partir da emergência da China e sua alta demanda por recursos naturais.

Atento a este impasse, Gladstone Leonel Júnior destaca a diversificação da dinâmica econômica prevista na NCPE como modo de aproximar-se do ideal do Vivir Bien ainda nos marcos do capitalismo(LEONEL JÚNIOR, 2015, p. 188). A expectativa é que o reforço da presença do Estado em setores estratégicos ampliaria a perspectiva proativa na participação e na vida do povo boliviano, de tal forma que seja possível dar corpo à economia comunitária e social cooperativa como o próximo passo.

Além da já mencionada nacionalização de empresas petrolíferas, o autor menciona a experiência embrionária de produção da bateria ión-lítio a partir da exploração de recursos evaporíticos no Salar de Uyuni, operada pelo governo boliviano, com uma política de gestão de políticas ambientais, em ações que compreendem a incineração dos resíduos sólidos(LEONEL JÚNIOR, 2015, p. 198). A apreensão pelo Estado Plurinacional - e o 
direcionamento aos setores populares - de toda cadeia produtiva seria um passo importante para a superação da dependência, tornando a economia boliviana menos vulnerável a ingerências políticas de toda ordem, principalmente a partir de interesses de organizações privadas inter, multi ou supranacionais.

\section{CONCLUSÃO}

Movimentos sociais e autores da corrente ecossocialista (LOWY; KOVEL, 2001) denunciam que a expansão do capitalismo é possibilitada a partir da mercantilização de todas as dimensões da vida social, incluindo nela a natureza e os bens comuns. O modo produtivista de produção capitalista, orientado teleologicamente no paradigma moderno do "progresso" e do "desenvolvimento", esbarra nos limites materiais dos recursos naturais disponíveis e usufruíveis. Nesta lógica, inexistem possibilidades e alternativas aos grandes dilemas ambientais dentro do capitalismo (FOSTER, 2005).

O capitalismo assume no Sul Global, especialmente na América Latina, características próprias relacionadas aos marcos da dependência. Os processos de colonização geraram padrões de produção que imputam aos países dependentes o papel de exportadores de matérias primas sob a lógica da superexploração do trabalhador na divisão internacional do trabalho. A Bolívia é um expoente histórico desta dinâmica, combinando todos seus elementos: apropriação dos recursos naturais, extermínio e exploração de classes subalternas, e processos políticos autoritários construídos de cima pra baixo.

Não é possível falar em democracia sem relacioná-la a elementos de libertação e emancipação das classes oprimidas e subalternizadas. A democracia, entendida na sua substância material de (re)tomada do controle sobre todas as dimensões da vida, assume especial relevo quando relacionada à interação coletiva e harmoniosa com os bens comuns. Cidadania ativa e meio ambiente se tornam conceitos intrínsecos a análises de processos que objetivam maior densidade democrática. Se a deliberação coletiva não perpassa os modos de os seres humanos se relacionarem com o ambiente, ou seja, sobre as possibilidades de reprodução saudável de nossas vidas; para que ela serve?

O processo boliviano das últimas décadas é um exemplo vivo da imbricação destes elementos. Novos e tradicionais sujeitos coletivos se constituem como atores na cena democrática, produzindo novos arranjos institucionais e inventando alternativas de/ao desenvolvimento a partir da relação com a Pachamama. O reconhecimento das demandas e 
direitos na NCPE não pode ser encarado como um produto acabado, mas como um processo permanentemente em construção.

A Bolívia do Bien Vivirestá inserida numa dinâmica global capitalista e ainda são muitos os desafios de superação das heranças coloniais, a concretização do programa contido na Carta Magna está sujeito às relações materiais e coloniais de poder. Um renovado extrativismo se apresenta como o principal impasse de um país que ainda não encontrou alternativas viáveis para superar sua condição de miserabilidade sem cair na armadilha predadora da degradação ambiental.

Para que serve, pois, o Vivir Bien, já que ele parece se afastar na medida em se tenta se aproximar dele? Ja diziam Eduardo Galeano e Fernando Birri sobre a utopia: para que os povos subalternos não deixem de persegui-lo.

\section{REFERÊNCIAS}

ACOSTA, Alberto. O Bem Viver. São Paulo: Editora Elefante, 2016.

ALBÓ, Xavier. Movimientos y poder indígena en Bolivia, Ecuador y Perú. La Paz: CIPCA, 2009.

BELLO, Enzo. O pensamento descolonial e o modelo de cidadania do novo constitucionalismo latino-americano. Revista de Estudos Constitucionais, Hermenêutica e Teoria do Direito (RECHTD), v. 7, n. 1, p. 49-61, 2015. Disponível em: $<$ http://revistas.unisinos.br/index.php/RECHTD/article/view/rechtd.2015.71.05>. Acesso em: $14 / 05 / 2016$.

Cidadania, alienação e fetichismo constitucional. In: BELLO, Enzo; LIMA, Martonio Mont'Alverne Barreto. (Org.). Direito e Marxismo. Rio de Janeiro: Lumen Juris, 2010, p. $07^{19}-33$.

BOLÍVIA. Constituição (2009). Constituição do Estado Plurinacional da Bolívia: promulgada em 7 de fevereiro de 2009.

BORÓN, Atilio. América Latina en lageopolítica del imperialismo. Buenos Aires: Luxemburg, 2014.

CABEZAS, Marta. Caracterización del "Ciclo Rebelde" 2000-2005. In: LÓPEZ, Jesús Espasandín; IGLESIAS TURRIÓN, Pablo. (Org.). Bolivia en movimiento:acción colectiva y poder político. Editorial El Viejo Topo, 2007.

CENEDET. Ni colonialistas ni simpáticos: resposta a Eduardo Gudynas, 2015. Disponívelem: https://lalineadefuego.info/2015/10/13/ni-colonialistas-ni-simpaticos-unarespuesta-a-eduardo-gudynas/. Acesso em: 16/08/2016. 
FOSTER, John Bellamy. A ecologia de Marx: Materialismo e Natureza. Rio de Janeiro: Civilização Brasileira, 2005.

GARCÍA LINERA, Álvaro. La potencia plebeya:acción coletiva e identidades indígenas, obreras y populares em Bolivia. Buenos Aires: Prometeu Libros y CLACSO, 2008.

_. El pueblo boliviano vive la mayor revolución social. Entrevista, 2012. Disponível na internet em: http://www.vicepresidencia.gob.bo/IMG/pdf/entrevista_la_jornada_de_mexico.pdf.

Acessoem: 23.05.2016.

GUDYNAS, Eduardo. Romper com um colonialismo simpático, 2015.Disponívelem: http://www.la-razon.com/index.php?_url=/suplementos/animal_politico/Rompercolonialismo-simpatico_0_2351764865.html. Acesso em: 16/08/2016.

Más allá del nuevo extractivismo: transiciones sostenibles y alternativas al desarrollo. In: Fernanda Wanderley (Org.). El desarrollo en cuestión. Reflexiones desde América Latina. La Paz: Ed. Oxfam y CIDES UMSA, 2011.

Diez tesis urgentes sobre el nuevo extractivismo. Contextos y demandas bajo el progresismo sudamericano actual. In: Extractivismo, política y sociedad. Quito: CAAP (Centro Andino de Acción Popular) y CLAES (Centro Latino Americano de Ecología Social), 2009.

GUIMARÃES, Alice Soares. A Reemergência de Identidades Étnicas na modernidade: movimentos sociais e Estado na Bolívia contemporânea. Rio de Janeiro: Ed. UERJ, 2014.

LEONEL JÚNIOR, Gladstone. O Novo Constitucionalismo Latino-americano: um estudo sobre a Bolívia. Rio de Janeiro: Lumen Juris, 2015.

LÖWY, Michael; KOVEL, Joel. Manifesto Ecossocialista Internacional. Manuscrito, 2001. MARINI, Ruy Mauro. Dialética da dependência. Petrópolis: Vozes, 2000.

MIGNOLO, Walter. Desobediencia epistémica: retórica de la modernidad, lógica de la colonialidad y gramática de la descolonialidad. Buenos Aires: Ediciones del Signo, 2010.

O'CONNOR, James. Natural Causes: Essays in Ecological Marxism. New York: Guilford Press, 1998.

PAZ, Sarela. La Marcha Indígena del TIPNIS en Bolivia y su relación con los Modelos Extractivos de América del Sur. GEOGRAPHIA, Niterói, volume 13, número 26. 2012. Disponível na internet em: http://www.uff.br/geographia/ojs/index.php/geographia/article/view/453/324. Acesso em: 19.07.2016.

PORTO GONÇALVES, Carlos Walter; HURTADO, Lina M.; BETANCOURT, Milson. Tensiones territoriales y políticas públicas de desarrollo en la Amazonia: los casos del territorio indígena y Parque Nacional Isiboro-Secure en Bolivia y el Área de Manejo Especial de la Macarena en Colombia. Colección: Secretaría Ejecutiva de CLACSO, Buenos Aires, dezembro, 2013. Disponível na internet em: R. Fac. Dir. UFG, v. 41, n.1, p. 103-121, jan./jun. $2017 \quad$ ISSN 0101-7187 
http://biblioteca.clacso.edu.ar/clacso/becas/20131223125249/TrabajoFinal.pdf. Acesso em: 18.05.2016.

PRADA, Raul. En torno al TIPNIS. 2011. Disponível na internet em: http://www.icees.org.bo/art-colaboracion/En\%20torno\%20al\%20TIPNIS.pdf. Acessoem: 25.07.2016.

Miseria de la Geopolítica. 2012. Disponível na Internet em: http://www.rebelion.org/docs/157961.pdf. Acessoem: 20.07.2016.

QUIJANO, Aníbal. Colonialidad del poder, eurocentrismo y América Latina. In: LANDER, Edgardo (comp.). La colonialidad del saber: eurocentrismo y ciencias sociales. Perspectivas Latinoamericanas. Buenos Aires: CLACSO - Consejo Latinoamericano de Ciencias $\quad 2000 . \quad$ Sociales, Disponível em: http://bibliotecavirtual.clacso.org.ar/ar/libros/lander/quijano.rtf. Acesso em 10.05.2016.

\footnotetext{
${ }^{1}$ A primeira contradição é a exploração dos proletários pela burguesia, exposta na tradicional crítica de Karl Marx e Friedrich Engels, contemporaneamente atualizada após análises de outras faces da subordinação: gênero, raça, etnia e geopolítica.

${ }_{2}$ A terminologia aqui adotada ("Vivir Bien") reproduz o termo utilizado pela Nueva Constitución Política del Estado Plurinacional de Bolívia, de 2009, ao passo que a Constitución de la República del Ecuador, de 2008, usa a nomenclatura "Buen Vivir". No Brasil, acadêmicos, pesquisadores e militantes de movimentos sociais têm falado em "Bem Viver".

${ }^{3}$ Em que pese a argumentação de alguns autores como Walter Mignolo (MIGNOLO, 2010), que consideram o marxismo como uma grande narrativa da modernidade europeia - portanto, distante dos elementos genuínos da América Latina -, sustentamos a viabilidade, a pertinência e a utilidade da articulação entre o campo do marxismo e pensamento descolonial. Entendemos que se trata de visões confluentes em termos críticos, para se pensar e agir sobre a realidade contemporânea, tendo em vista alguns elementos em comum: (i) referência a partir da materialidade das relações sociais; (ii) visão a partir dos sujeitos oprimidos em relações de dominação; (iii) objetivos transformação social, fundamentalmente através da redistribuição de riquezas e do alcance da igualdade material, entre outros. Essa argumentação é mais desenvolvida no texto "Direitos humanos e emancipação/liberação: possíveis aproximações entre marxismo e descolonialismo", no prelo.

${ }^{4}$ No original: "articulación política de las experiencias cotidianas de exclusión social, discriminación étnica y memória social comunitaria de campesinos indios dejados a su suerte por un Estado empresário".

${ }^{5}$ No original: "cohesionará una fuerza de maza movilizable, insurreccional, y electoral, logrando politizar el campo político discursivo y consolidándose como una ideología con proyección estatal".

${ }^{6} \mathrm{O}$ pacto de unidade celebrado foi em setembro de 2004 entre a Confederación Sindical Única de Trabajadores Campesinos de Bolivia (CSUTCB), Confederación Sindical de Comunidades Interculturales de Bolivia (CSCIB), a Confederación Nacional de Mujeres Campesina Indígena Originarias de Bolivia "Bartolina Sisa” (CNMCIOB - BS), a Confederación de Pueblos Indígenas del Oriente Boliviano (CIDOB) e o Concejo Nacional de Ayllus y Markas del Qullasuyu (CONAMAQ). A sua dissolução ocorre em janeiro de 2013 com a saída da CIDOB-CONAMAQ, justificada na relativização, pelo poder executivo, da participação social das comunidades indígenas nas decisões que afetam diretamente seus territórios, culturas e recursos naturais.

${ }^{7}$ O TIPNIS localiza-se na Amazônia Andina e compreende quatro municípios em seu território: Ignacio de Moxos e Loreto no Estado de Beni e Villatunari y Morochota no Estado de Cochabamba. Nelehabitamtrês povos originários - Yuracarés, Tsimanes e Mojeño-Sécure -, cuja economia está baseada na caça, na pesca e na agricultura, com alguma variação entre os povos, constituindo-se economias étnicas de caráter comunitário, baseada no acesso comum aos bens que garantem a vida e a reprodução das famílias (PORTO GONÇALVES; HURTADO; BETANCOURT, 2013, 28).

${ }^{8}$ A Iniciativa para a Integração da Infraestrutura Regional Sul-Americana (IIRSA) é um programa conjunto dos governos dos 12 países da América do Sul que visa a promover a "integração sul-americana" através da integração física desses países, com a modernização da infraestrutura de transporte, energia e telecomunicações, mediante ações conjuntas. O Eixo Andino (Venezuela, Colômbia, Equador, Peru, Bolívia) compreende a integração energética, com destaque para a construção de gasodutos. O Eixo Interoceânico Central (Sudeste brasileiro, Paraguai, Bolívia, norte do Chile, sul do Peru) prevê rede de transportes para exportar produtos agrícolas brasileiros e minerais bolivianos pelo Pacífico. O Eixo Peru-Bolívia-Brasil objetiva a criação de um eixo transportes envolvendo o Brasil, Bolívia e Peru, com a conexão portuária peruana no Pacífico, permitindo a expansão do comércio destes países com a Ásia. Diversos movimentos e entidades denunciam que a iniciativa, ao contrário de promover a real integração entre os países, possibilitou uma interconexão de mercados e a expansão da degradação ambiental.

${ }^{9}$ Diante do imbroglio, a concessão foi revista em 2012.

${ }^{10}$ As r. leis foram objeto de ações de controle abstrato de constitucionalidade ajuizadas por deputados e senadores da Asamblea Legislativa Plurinacional e julgadas pelo Tribunal Constitucional Plurinacional de Bolivia na Resolución R. Fac. Dir. UFG, v. 41, n.1, p. 103-121, jan. / jun. 2017

ISSN 0101-7187
} 
0300/2012. Os autores Miguel Ángel Ruíz Morales (MAS) e Zonia Guardia Melgar (MAS) alegaram, entre outras coisas, que a declaração de intangibilidade do território pela Ley $n$. 180 impedia o Estado de cumprir suas obrigações constitucionais com a sociedade e, em especial, com os povos do TIPNIS. Os deputados Fabián II Yaksic Feraudy (MAS) e Miriam Marcela Revollo Quiroga (MAS), por sua vez, acerca da Ley n. 222, alegaram não se tratar de uma consulta prévia, livre e informada, mas uma pseudo consulta posterior a diversos atos e feitos administrativos e legislativos efetuados pelo Governo sem que houvesse consulta alguma. A corte constitucional decidiu pela improcedência do pedido de declaração de inconstitucionalidade da Ley n. 180 e, em suma, declarou constitucional a Ley n. 222, condicionada, entretanto, à produção de um arranjo, instando os povos do TIPNIS a estabelecerem um diálogo com o Estado, a Asamblea Nacional a mediar o acordo e ao Executivo para cumpra suas obrigações constitucionais, resguardando não só os interesses dos povos do TIPNIS, mas também o interesse nacional.

${ }^{11}$ Sobre os sentidos do TIPNIS, vale destacar os comentários de Raul Prada: "Para os povos indígenas o TIPNIS é o monte sagrado; para os ecologistas é o coração da produção da água, dos ciclos de água das zonas do TIPNIS e das regiões adjacentes. Para a Constituição é uma TCO, um território indígena e parque, onde co-habitam as comunidades indígenas de três povos amazónicos, yuracarés, chimanes e moxeños, os mesmos que gozam de direitos coletivos, consagrados pela Constituição. O conflito do TIPNIS se converteu no centro dos debates e na batalla crucial em defesa da Madre Tierra, da Constituição e do processo. O ocorrerá depende da capacidade de resistência das comunidades da TCO do TIPNIS, também da violência que é capaz de exercer o Governo" (PRADA, 2012, 34)

. No original:"Para los pueblos indígenas el TIPNIS es la loma santa; para los ecologistas es el corazón de la producción del agua, de los ciclos de agua de las zonas del TIPNIS y de las regiones colindantes. Para la Constitución es una TCO, un territorio indígena y parque, donde cohabitan las comunidades indígenas de tres pueblos amazónicos, yuracarés, chimanes y moxeños, los mismos que gozan derechos colectivos, consagrados por la Constitución. El conflicto del TIPNIS se ha convertido en el centro de los debates y en la batalla crucial en defensa de la Madre Tierra, de la Constitución y del proceso. Lo que vaya a ocurrir depende de la capacidad de resistencia de las comunidades de la TCO del TIPNIS, también de la violencia que es capaz de ejercer el Gobierno".

${ }^{12}$ No original: "Las personas tienen derecho a un medio ambiente saludable, protegido y equilibrado. El ejercicio de este derecho debe permitir a los individuos y colectividades de las presentes y futuras generaciones, además de otros seres vivos, desarrollarse de manera normal y permanente".

${ }^{13}$ No original: "En este caso se repite la apropiación masiva de recursos naturales para exportación, por medio de enclaves productivos, y se repiten los impactos sociales y ambientales. Pero el protagonismo estatal es mayor, y en unos casos aparece bajo la forma de controles más rigurosos, mayores niveles de tributación o regalías, o por el regreso de empresas estatales a hacerse cargo de distintos proyectos"

${ }^{14} \mathrm{Tal}$ oposição aparece recentemente em debates acadêmicos sobre os usos da categoria "acumulação via espoliação" do geógrafo inglês David Harvey por progressistas na América do Sul. A noção, reputada como "ampla e incompleta", seria aplicável em diversas situações de expropriação do trabalho e dos recursos naturais no globo e acabaria por ocultar as características peculiares do processo latino-americano. Os governos progressistas, ao utilizarem-se do conceito para depositar suas contradições em um elemento externo (supra-nacional), invisibilizariam as críticas produzidas desde as lutas dos sujeitos coletivos e dos saberes locais. Deste modo, estariam caracterizados a "moda Harvey" e o "colonialismo simpático". Seu texto foi prontamente rebatido pela equipe de investigadores do Centro Nacional de Estratégias para el Derecho al Territorio, fundado por David Harvey no Equador, que afirmam, entre outras coisas, a ampla validade da produção acadêmica do autor, tanto para os movimentos de oposição ao extrativismo, quanto para os governos inseridos numa dinâmica capitalista global. v. GUDYNAS, Eduardo. Romper com um colonialismo simpático, 2015. Ddisponível em http://www.la-razon.com/index.php?_url=/suplementos/animal_politico/Romper-colonialismosimpatico_0_2351764865.html e CENEDET. Ni colonialistas ni simpáticos: Resposta a Eduardo Gudynas, 2015. Disponível em https://lalineadefuego.info/2015/10/13/ni-colonialistas-ni-simpaticos-una-respuesta-a-eduardo-gudynas/.

${ }^{15}$ No original: "la llegada al gobierno de Evo Morales y el MAS en Bolivia, rapidamente desemboco en un cambio sustancial en la imposición tributaria y regalías de las empresas, renegociación de los contratos, y un Estado que deja de ser un mero espectador y pasa a constituirse en un actor clave para esos sectores".

${ }^{16}$ No original: Los dos proyectos no pueden coexistir en el proceso, son opuestos; uno se coloca en la continuidad de la misma civilización moderna, capitalista, desarrollista y extractivista, el otro apunta a abolir esta civilización, abriendo la posibilidad civilizatoria alternativa haciendo emerger configuraciones culturales inhibidas por los colonialismo y el capitalismos, actualizándolos y combinándolos con formas autogestionarias y solidarias contemporáneas. Este proyecto se opone abiertamente al desarrollismo y al extractivismo, se encamina más bien a restaurar las complementariedades dinámicas con los ecosistemas, seres, ciclos vitales interrelacionados e integrados en las formas complejas de reproducción de la vida. No debe sorprendernos entonces los conflictos que se dan entre el gobierno y las naciones y pueblos indígenas originarios, pues el gobierno se ha convertido en la expresión política e institucional del proyecto de continuidad capitalista, desarrollista, extractivista y de monocultivos. ¿Por qué ha sucedido esto? La contradicción era latente, solo que no tuvo las condiciones de posibilidad para mostrarse; una cosa era luchar contra los gobiernos neoliberales y el proyecto neoliberal en curso y otra cosa es abolir el Estado-nación, construir el Estado plurinacional comunitario y autonómico, en la perspectiva del modelo civilizatorio del Vivir Bien, que se basa en el respeto de los derechos de los seres, componentes y ciclos vitales de la Madre Tierra".

${ }^{17}$ No original: "En algunas versiones, este pachamamismollegó tan lejos como para exigir a los gobiernos de los países de izquierda el abandono de cualquier pretensión de explotar recursos naturales, colocando a aquellos ante un cruel y difícil dilema: como conciliar la necesidad de responder a las renovadas demandas de justicia distributiva - elevadas por la población que han sufrido siglos de opresión y miséria - con la intangibilidad de la naturaleza?" 
${ }^{18}$ No original: "El extractivismo no es un destino; puede ser un punto de partida para su superación. Ciertamente en el extractivismo se condensa toda una distribución territorial de la división del trabajo mundial, distribución colonial. Pero para romper esa subordinación colonial no es suficiente llenarse la boca de injurias contra el extractivismo, dejar de producir y hundir en mayor miseria al pueblo, para que luego regrese la derecha y mediante el extractivismo satisfaga parcialmente las necesidades básicas de la población. Esta es precisamente la trampa conservadora de los críticos del extractivismo. En su liturgia conservacionista, mutilan a las fuerzas revolucionarias y a los gobiernos revolucionarios de los medios materiales para satisfacer las necesidades de la población, para generar riqueza y distribuirla con justicia, y crear sobre ello una nueva base material no extractivista que preserve y amplié los beneficios de la población laboriosa".

Artigo recebido em 04 de setembro de 2016 e aceito em 05 de junho de 2017 